\title{
ASSESSMENT OF MEAN DISTANCE OF MANDIBULAR INCISIVE CANAL USING CONE BEAM COMPUTERIZED TOMOGRAPHY; A CROSS-SECTIONAL STUDY
}

\author{
Mubashir Sharif, Nighat Haroon*, Muhammad Anwaar Alam**, Adil Umar Durrani***, Talib Hussain****, Khawar Anwar***** \\ 21 MDC, Quetta Pakistan, *Lahore General Hospital, Lahore Pakistan, **Azra Naheed Dental College, Lahore Pakistan, ***Foundation University College of \\ Dentistry \& Hospital, Rawalpindi Pakistan, ${ }^{* * * * W o m e n ~ D e n t a l ~ C o l l e g e, ~ A b b o t t a b a d ~ P a k i s t a n, ~}{ }^{* * * * * F r o n t i e r ~ M e d i c a l ~ C o l l e g e, ~ A b b o t t a b a d ~ P a k i s t a n ~}$
}

\section{ABSTRACT}

Objective: To determine the mean distance of mandibular incisive canal from the mental foramen in patients reporting to a tertiary care centre using Cone Beam Computerized Tomography for placement of dental implants in the anterior/interforaminal region.

Study Design: Cross-sectional study.

Place and Duration of Study: Department of Prosthodontics, Foundation University College of Dentistry Rawalpindi, Jun to Nov 2019.

Methodology: A total of 70 patients participated between the age of 20-45 years. Cone Beam Computerized Tomography (the investigation was carried out and measurements of the mandibular incisive canal from mental foramen were recorded with the help of measuring tools in the software and noted down on the proforma. Data were analyzed using SPSS-20.

Results: The number of patients selected for this study was 70. Out of these 70 patients, 33 (47.1\%) were males and $37(52.9 \%)$ were females. The mean age of patients in this study was $36.31 \pm 6.38$ years. The mean distance/extension of the mandibular incisive canal from left mental foramen and right mental foramen in all patients was recorded to be $14.49 \pm 6.31 \mathrm{~mm}$ and 14.97 $\pm 7.10 \mathrm{~mm}$ respectively.

Conclusion: Within the limitations of this study, it is concluded that a maximum distance of $22 \mathrm{~mm}$ of the incisive canal from the mental foramen was observed using cone-beam computerized tomography.

Keywords: Cone-beam computerized tomography, Dental implant, Mental foramen.

How to Cite This Article: Sharif M, Haroon N, Alam MA, Durrani AU, Hussain T, Anwar K. Assessment of Mean Distance of Mandibular Incisive Canal Using Cone Beam Computerized Tomography; A Cross-Sectional Study. Pak Armed Forces Med J 2021; 71(5): 1801-1805. doi: https://doi.org/10.51253/pafmj.v71i5.7287

This is an Open Access article distributed under the terms of the Creative Commons Attribution License (https://creativecommons.org/licenses/by-nc/4.0/), which permits unrestricted use, distribution, and reproduction in any medium provided the original work is properly cited.

\section{INTRODUCTION}

The information regarding the anatomy of the anterior region of the mandible is of utmost importance before carrying out any boney and/or soft tissue surgical procedure in this segment. Although the general concept being that the inter-foraminal region of the mandible is a safe location for dental implant placement and other surgical procedures, anatomical variations do exist among different populations. ${ }^{1}$ Mental for a-men (MF) allows the passage of the terminal branch of the inferior alveolar nerve (IAN) which is known as the mental nerve. The IAN may also continue into the anterior region of the mandible in the form of the Incisive nerve. ${ }^{2}$ Certain studies have suggested that nerve and blood vessels may course through the intertrabecular spaces of the mandibular anterior region. Variations in the extent of the incisive canal (IC) in the mandibular anterior region have been associated with geography, gender and whether the patient is dentate or edentulous. ${ }^{3,4}$ It is of utmost importance to appreciate

Correspondence: Dr Mubashir Sharif, Department of Prosthodontics, 21 MDC, Quetta Pakistan

Received: 23 Aug 2021; revision received: 04 Oct 2021; accepted: 06 Oct 2021 the anatomy of this region to avoid any injury to the neurovascular bundles. Sensory dysfunction may occur when the mandibular incisive nerve is damaged during an under implant placement procedure or any surgical procedure involving the anterior region of the mandible. ${ }^{5}$ The sensory dysfunction in the bicuspids, canines and incisors occur as a complication during placement of the implant in the anterior mandibular region. Sensory adversely affects the patient's quality of life. ${ }^{6}$

The use of Orthopantomograms (OPG) is a common investigation in dentistry to get an overview of all the dentition and its surrounding structures, that is, hard tissues. Although the accuracy and precision of OPG in the detection of accurate location of MF and the presence of IC may be considered questionable. ${ }^{7}$ It is, therefore, necessary to have a clear vision/image of the jaw to prevent these damages, which can be achieved by a combination of clinical and anatomical knowledge of mandibular structures and with the help of findings obtained from clinical and radiological examination ${ }^{8}$. Thus, revisiting the anatomy of the mandibular anterior region with the 3D imaging technique, 
that is, Cone-beam computerized tomography (CBCT), will provide a better image quality/resolution and an accurate representation of the structures with a low radiation dose. ${ }^{7,9}$

The rationale of our study was to determine the mean distance of mandibular incisive canal from the mental foramen in patients reporting to a tertiary care centre using CBCT for placement of dental implants in the anterior/inter-foraminal region thus determining the estimated safe zone implant placement in the presence of mandibular incisive nerve.

\section{METHODOLOGY}

This cross-sectional study was carried out in the Prosthodontics department, Foundation University College of Dentistry, Islamabad, from June to November 2019, After approved by Ethics Review Committee, Foundation University College of Dentistry, Islamabad (FUCD/ERC-5/25-2019).

A sample size of 70 patients (52 calculated) was selected for this study, calculated with the help of WHO sample size calculator. The parameters used for sample calculation using WHO sample size calculator were: Confidence level: 95\%, anticipated population proportion: $96.5 \% 10$, absolute precision required: $5 \%$ and calculated sample size: 52. A non-probability consecutive sampling technique was used for data collection.

Inclusion Criteria: The patients of both male and female gender with age ranging from 20-45 years, patients for whom CBCT has been advised as part of their treatment, patients with no history of mandibular symphyseal or Para symphyseal fracture, both partially dentate and completely edentulous patients were selected and patients with no history of tumors, cyst or any other bony deformity in the anterior region of mandible, Patients who brought their old CBCT investigation were also considered in this study provided they fulfill the rest of the criteria.

Exclusion Criteria: The patients with a history of tumors, cyst or any other bony deformity involving the anterior portion of the mandible within the region of right and left mandibular $1^{\text {st }}$ molar or presence of any radiolucent lesion in the lower jaw in the same region, patients with any jaw growth deformity, patients with any identifiable syndrome, patients on bisphosphonate therapy, patients with osteoporosis and non-visualization of the mental foramen bilaterally.

As a protocol all patients presenting to hospital were examined in dental OPD/diagnostics department and patients with prosthodontic needs were referred to Prosthodontics department. Those patients who fulfilled the criteria (Exclusion and Inclusion) were selected for the study. Patients in whom CBCT was required where advised the investigation done any nearest laboratory with the facility of this investigation. Most patients reported 3D radiographic images of the patient which were recorded using Newtom vgi CBCT (Verona, Italy). Measurements of the MF from the mandibular Symphysis/midline and presence and extent/ distance of mandibular incisive canal were recorded using a measuring tool in panorex view, cross section (Figure-1) and 3D model (Figure-2) in the software (NNT viewer) provided with CBCT disc of patient or using an open-source software (Blue Sky Bio). The measurements recorded were filled in the Performa for each patient separately.

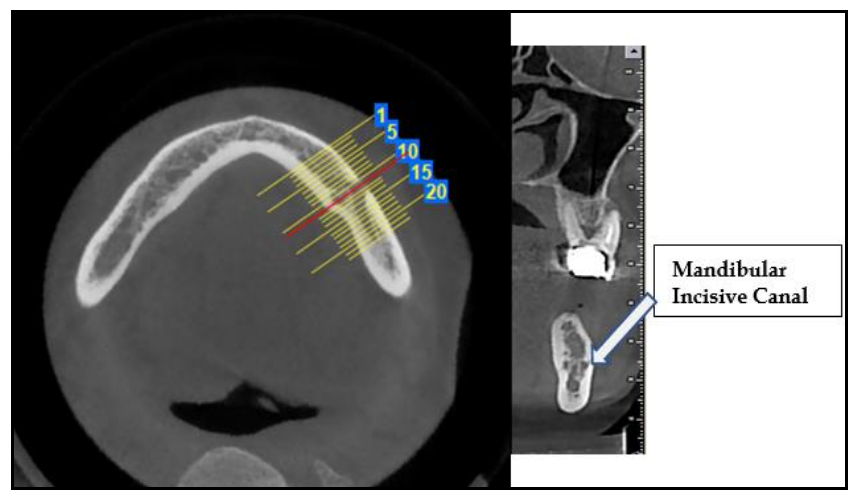

Figure-1: Cross-Sectional cut of mandible to identify the extent of mandibular incisive canal from mental foramen with the help of nnt viewer software.

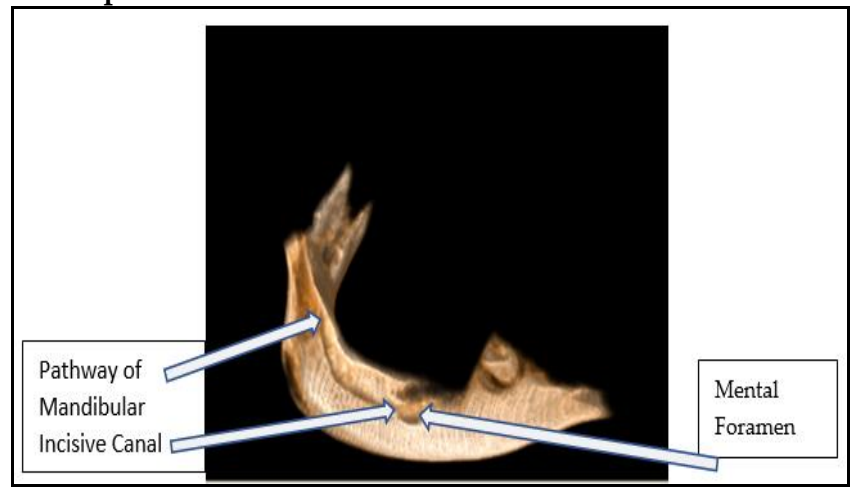

Figure-2: 3D Cut model of mandible of the patient showing presence of mandibular incisive canal.

SPSS-20 was used analyze the data. Descriptive statistics were calculated for both qualitative and quantitative variables. Frequency and percentages were calculated for variable gender (qualitative). For quantitative variables like age, distance MF from the mandibular Symphysis and distance/extent of IC, mean \pm 
SD were calculated. Independent samples t-test was used to determine the difference in quantitative variables like distance/extent of mandibular incisive canal in the anterior region of mandible between left and right side. The $p$-values of $\leq 0.05$ was considered statistically significant.

\section{RESULTS}

The number of subjects selected for this study was 70. Out of these, patients $33(47.1 \%)$ were males and $37(52.9 \%)$ were females. The Mean age of patients in this study was $36.31 \pm 6.38$ years. Out of 70 patients, 11 $(15.7 \%)$ was completely edentulous and 59 (84.3\%) were partially dentate patients.

The mean distance of the left mental foramen (LMF) and Right Mental Foramen (RMF) from the mandibular symphysis/midline of all patients was $24.15 \pm 2.86$ millimetres $(\mathrm{mm})$ and $24.89 \pm 2.67 \mathrm{~mm}$ respectively. The mean distance/extension of the mandibular incisive canal (MIC) from LMF and RMF in all patients was recorded to be $14.49 \pm 6.31$ and $14.97 \pm$ 7.10 respectively. The mean distance/extension of the mandibular incisive canal from LMF and RMF in males was recorded to be $17.07 \pm 3.62$ and $16.98 \pm 4.10$ respectively. The mean distance/extension of the mandibular incisive canal from LMF and RMF in females was recorded to be $12.18 \pm 7.28$ and $13.18 \pm 8.64$ respectively.

Paired sample t-test was applied to determine the difference between the extension/distance of IC on the left and right sides. A statistically significant difference was found between the extension/distance of IC on the left and right side, with at (69) $=-2.144$ and a $p$-value of 0.036. An independent sample t-test was used to determine the difference in the extension/distance of the Mandibular incisive canal between dentate and edentulous patients. A statistically significant difference was noted in the extension/distance of IC on the left and right side between dentate and edentulous patients, with a $p$-value of 0.006 and 0.001 respectively.

\begin{tabular}{|c|c|c|c|}
\hline \multirow[t]{2}{*}{ Gender } & \multicolumn{2}{|c|}{$\begin{array}{c}\text { Distance of Mandibular Incisive Canal } \\
\text { on Left Side ( } \mathrm{mm})\end{array}$} & \multirow[t]{2}{*}{$\begin{array}{c}p- \\
\text { value }\end{array}$} \\
\hline & $\mathrm{n}$ & Mean \pm SD & \\
\hline Male & 33 & $17.07 \pm 3.62$ & \multirow[t]{2}{*}{0.244} \\
\hline \multirow[t]{3}{*}{ Female } & 37 & $12.18 \pm 7.28$ & \\
\hline & \multicolumn{2}{|c|}{$\begin{array}{c}\text { Distance of Mandibular Incisive Canal } \\
\text { on Right Side (mm) }\end{array}$} & \\
\hline & $\mathrm{n}$ & Mean \pm SD & \\
\hline Male & 33 & $16.98 \pm 4.10$ & \multirow[t]{2}{*}{0.665} \\
\hline Female & 37 & $13.18 \pm 8.64$ & \\
\hline
\end{tabular}

There was a statistically significant difference in the extension/distance of the left and right Mandibular incisive canal between males and females, with a $p$ value of 0.001 and 0.024 respectively (Table). An independent sample t-test was used to determine the association in the extension/distance of mandibular incisive canal between age groups (divided into 2 groups, that is, group-I: 20-32 years and group-II: $33-45$ years). Statistically, no significant difference was found in the extension/distance of left and right Mandibular incisive canal with respect to age groups with a $p$-value of 0.414 and 0.985 respectively.

\section{DISCUSSION}

It is critical to detect the objective location of MF as well as the presence and extent of the mandibular incisive canal (MIC) before proceeding with the surgical treatment in the mandibular anterior region to avoid any chance of potential injury to the neurovascular bundle during surgery. The possible surgical procedures performed in this region may be dental implant placement, apicectomy, cyst removal or preprosthetic surgery or any other surgical procedure. The precise location of these vital structures becomes even important when performing surgical procedures in completely edentulous patients. ${ }^{9-12}$ This study aimed at evaluating the average location of MF, as well as analyzing the appearance and length/extent of MIC. Dimorphism and differences between left and right sides were also analyzed.

Numerous studies have been conducted to locate the position of MF in relation to the roots of a tooth namely canine, $1^{\text {st }}$ premolar and $2^{\text {nd }}$ premolar. ${ }^{11-16}$ The limitations of such studies is that they are only helpful in a dentate patient in which these teeth are present which would otherwise be of little if any help when it comes to implant therapy in completely edentulous patients. The position of the teeth in itself is variable and in situations of malocclusion or congenitally missing or impacted canines or in cases of retained deciduous, this relative positioning would again be of no help. This is why we used measurements from specific hard tissue landmarks to determine the position of the mental foramen. These landmarks are stable and do not change whether the individual is dentate or edentulous thus giving a much more accurate location of mental MF. ${ }^{17}$ In a study conducted by Budhiraja and colleagues, the distance of the anterior border of MF from symphysis on the left and right side were 25.29 \pm 0.30 and $25.39 \pm 0.66$ respectively. ${ }^{17}$ These measurements are to a certain extent different but closer to 
measurements from that recorded in our population, that is, $24.15 \pm 2.86$ millimetres $(\mathrm{mm})$ and $24.89 \pm 2.67$ $\mathrm{mm}$ respectively. This difference highlights the fact that ethnicity does play a role in the variation in the position of mental foramen and should not be ignored.

In one of the studies, the incidence of MIC anterior to MF was found in $92 \%$ of the mandibles out of 105 mandibles. ${ }^{18}$ The results of our study also suggest that a statistically significant difference was found in the extent of MIC among dentate and edentulous patients. In our study difference in the extent of MIC with respect age of the patient was also analyzed but no statistically significant difference was found. These findings suggest that the presence or absence of teeth in the anterior mandibular region may have some correlation with the extent of MIC whereas age may not have a strong relation. Although further studies may need to be carried out on a larger population to determine the correlation of dentition and age with the extent of MIC. As a part of treatment planning, it is always important to carry out the necessary investigations to identify the precise location of such anatomical structures to avoid any surgical complications.

In a study conducted by Genu et al, the mean length of MIC was observed to be $13.68 \mathrm{~mm}$ whereas Rosa et al, found a mean length of $9.11 \mathrm{~mm}$ in patients from Southeastern Brazil and Makris et al, using CBCT, found an average length of $15.1 \mathrm{~mm}$ in a Greek population.8,10,19 In our study left and right sides were separately recorded with a mean of $14.49 \pm 6.31 \mathrm{~mm}$ and $14.97 \pm 7.1 \mathrm{~mm}$ respectively. Significant variations have been noted in the extent of MIC in the above-mentioned studies which suggest that the ethnicity of the patient is an important consideration. None of the abovementioned studies observed significant differences in the length of MIC with respect to gender or sides. Although our study has conflicting results in this regard as the significant difference was found with respect to gender and sides with respect to the length of MIC.

Based on the comparison of the result of our study with those mentioned above in the discussion, it is important to note that variations are present among different populations and even in the same population there are variations among individuals. A Cone Beam Computerized Tomography imaging modality should be considered mandatory when performing any surgical procedure in the anterior mandible. This study would further broaden the horizon of the general dentist performing surgical procedures to be careful and a three-dimensional imaging modality when necessary.

\section{ACKNOWLEDGMENTS}

The authors thank all the technical staff who helped in data collection and interpretation.

\section{LIMITATION OF STUDY}

The limitations of our study, other than the small sample size, single-centre study and limited time period, were that we did not take into account the variation in the size, shape and direction of the Mandibular Incisive Canal. Numerous variations in the size, shape and direction of the Mandibular Incisive Canal have been reported in the literature. This information is crucial for dental implant placement in the interforaminal region where implant-supported prostheses are to be used for the replacement of missing teeth.

\section{CONCLUSION}

Within the limitations of this study, it is concluded that a maximum distance of $22 \mathrm{~mm}$ of the incisive canal from the mental foramen was observed using Cone Beam Computerized Tomography. The use of CBCT in the selection of adequate implant length is necessary to avoid damage to the nerve. Further studies on a larger population may be required to better estimate the length of the mandibular incisive canal.

\section{Conflict of Interest: None.}

\section{Authors' Contribution}

MS: Study design, data collection. NH: Data analysis and results. MAA: Discussion. AUD: Introduction \& methodology. TH: Results \& Discussion. KA: Statistical analysis.

\section{REFERENCES}

1. Panjnoush M, Rabiee ZS, Kheirandish Y. Assessment of location and anatomical characteristics of the mental foramen, anterior loop and mandibular incisive canal using cone-beam computed tomography. J Dent (Tehran) 2016; 13(2): 126-132.

2. Rodella L, Buffoli B, Labanca M, Rezzani R. A review of the mandibular and maxillary nerve supplies and their clinical relevance. Arch Oral Biol 2012; 57(4): 323-334.

3. Chrcanovic BR, Abreu MH, Custódio AL. Morphological variation in dentate and edentulous human mandibles. Surg Radiol Anat 2011; 33(3): 203-213.

4. Gawlikowska-Sroka A, Stocki Ł, Dąbrowski P, Kwiatkowska B, Szczurowski J, Czerwiński F. Topography of the mental foramen in human skulls originating from different time periods. Homo: internationale Zeitschrift für die vergleichende Forschung am Menschen, 2013; 64(4): 286-295.

5. Juodzbalys G, Wang HL, Sabalys G. Anatomy of mandibular vital structures. part-ii: mandibular incisive canal, mental for amen and associated neurovascular bundles in relation with dental implantology. J Oral Maxillofac Res 2010; 1(1): e3-e8.

6. Kim JE, Shim JS, Huh JB, Rim JS, Lee JY, Shin SW. Altered sensation caused by peri-implantitis: a case report. Oral Surg Oral Med Oral Pathol Oral Radiol 2013; 116(1): 13-18.

7. Misch CE. Contemporary implant dentistry. 3rd ed. St. Louis: Mosby 2008; 1(2): 8-15.

8. Makris N, Stamatakis H, Syriopoulos K, Tsiklakis K, van der Stelt PF. Evaluation of the visibility and the course of the mandibular 
incisive canal and the lingual foramen using cone-beam computed tomography. Clin Oral Implants Res 2010; 2(21): 766-771.

9. Parnia F, Moslehifard E, Hafezeqoran A, Mahboub F. Characteristics of anatomical landmarks in the mandibular interforaminal region: a cone-beam computed tomo-graphy study. Med Oral Patol Oral Cir Bucal 2012; 17(3): e420-425.

10. Genú PR, Vasconcellos RJH, Oliveira BP, Vasconcelos BCG, Delgado NCC. Analysis of anatomical landmarks of the mandibular interforaminal region using $\mathrm{CBCT}$ in a Brazilian population. Braz J Oral Sci 2014; 13(4): 303-307.

11. Juodzbalys G, Wang HL, Sabalys G. Injury of the inferior alveolar nerve during implant placement: a literature review. J Oral Maxillofac Res 2011; 2(1): e1-e5.

12. Liang X, Jacobs R, Corpas L, Semal P, Lambrichts I. Chronologic and geographic variability of neurovascular structures in the human mandible. Forensic Sci Int 2009; 190(1-3): 24-32.

13. Igbigbi PS, Lebona S. The position and dimensions of the mental foramen in adult Malawian mandibles. West Afr J Med 2005; 24(3): 184-189.
14. Mbajiorgu EF1, Mawera G, Asala SA, Zivanovic S. Position of the mental foramen in adult black Zimbabwean mandibles: a clinical anatomical study. Cent Afr J Med 1998; 44(2): 24-30.

15. Ngeow WC, Yuzawati Y. The location of the mental foramen in a selected Malay population. J Oral Sci 2003; 45(3): 171-175.

16. Chee $\mathrm{W}$, Jivraj $\mathrm{S}$. Treatment planning of the edentulous mandible. Br Dent J 2006; 201(6): 337-347.

17. Budhiraja V, Rastogi R, Lalwani R, Goel P, Bose SC. Study of position, shape, and size of mental foramen utilizing various parameters in dry adult human mandibles from north India. ISRN Anat 2012; 2013(4): 961429.

18. Obradovic O, Todorovic L, Pesic V, Pejkovic B, Vitanovic V. Morphometric analysis of mandibular canal: clinical aspects. Bull Group Int Rech Sci Stomatol Odontol 1993; 36(3-4): 109113.

19. Rosa MB, Sotto-Maior BS, Machado V de C, Francischone CE. Retrospective study of the anterior loop of the inferior alveolar nerve and the incisive canal using cone-beam computed tomography. Int J Oral Maxillofac Implants 2013; 28(2): 388-392. 